\title{
MAXIMUM SUSTAINABLE YIELD FOR THE PASSUR RIVER FISHERY OF BANGLADESH BY USING SURPLUS-PRODUCTION MODEL
}

\author{
Muhammad Abdur Rouf ${ }^{*}$, Sheik Istiak Md. Shahriar ${ }^{2}$, Md. Hafizur Rahman ${ }^{3}$, \\ Md. Mehedi Hasan ${ }^{1}$, Al-Hasan Antu ${ }^{1}$, and Md. Noman Siddiqui 4
}

Fisheries and Marine Resource Technology Discipline (FMRT), Khulna University Khulna 9208, Bangladesh

\begin{abstract}
Maximum sustainable yield (MSY), fishing effort $\left(f_{m s y}\right)$ and total allowable catch (TAC) of major fishery in the Passur River, Bangladesh were estimated using surplus production model (Schaefer and Fox model) with observation-error estimator based on four years (2011-2014) catch and effort data. Fox model was especially highlighted in this study; the estimated value of MSY was $4.61 \mathrm{~kg}$ with corresponding $f_{m s y}$ of 13.51 units $\left(200 \mathrm{~m}^{2} \mathrm{SBN} /\right.$ day). Moreover, the mean value of MSY and TAC with 95\% confidence interval in stochastic method was $4.53 \mathrm{~kg}$ and $4.08 \mathrm{~kg}$ respectively with the 13.22 units of fishing effort $\left(f_{m s y}\right)$. The overall results provide clear evidence that the fishery of the Passur River is being overexploited in the months from December to March. Sustainable exploitation of this stock can be assured through reducing present fishing effort. In addition, TAC might be incorporated along with several existing fisheries management measures to ensure the compensation of this stock towards long term sustainability.
\end{abstract}

Key words: Surplus production model, MSY, TAC, Passur River, Bangladesh.

\section{INTRODUCTION}

Inland capture fishery resources play a significant role in maintaining the livelihood of people in many parts of the world especially in developing countries (Allison and Ellis 2001). In Bangladesh, fish production from inland open water this is an old statistics, update data are available was 1.02 million MT in last year which was contributing about $27.79 \%$ of total USA fish production (DoF 2015). Unfortunately, in recent years the abundance of fishes from open water is gradually declining; might be due to increased fishing pressure, use of illegal nets, violation of fishing regulations and pollution (Mohsin et al. 2009; Imteazzaman and Galib 2013).

*Author for corresponding: <roufku@yahoo.com>, 2Dept. of Aquaculture, Hajee Mohammad Danesh Science and Technology University, Dinajpur-5200, Bangladesh, ${ }^{3}$ District Fisheries Office, Patuakhali, Bangladesh, ${ }^{4}$ Department of Biology, University of Louisiana at Lafayette, LA 70503,USA.

@2020 Zoological Society of Bangladesh DOI: https://doi.org/ 10.3329/ bjz.v48i2.52370 
Passur River is one of the largest (142 km in length) and economically significant rivers located in the southwestern part of Bangladesh (Chowdhury 2012). A large number of people directly or indirectly involved in fishing on this river for their livelihood. This River has been blessed with abundant fish and shellfish species (Gain et al. 2015). Different types of gear such as set bag net (SBN), gillnet, cast net, and entangled net, etc. are being used extensively to exploit the fishery resources of this river and the fish stock is expected to decline drastically. Thus, the people depend on this fishery faces threat on their income source. Despite a huge commercial demand of the river fishery, no published information is available on the stock assessment for the Passur River or even for river fisheries in Bangladesh. Therefore, estimating the total fish biomass or stock and the level of sustainable fish exploitation are urgently required for accelerating the management of this river fisheries. Surplus production models or biomass dynamic models have been extensively used as efficient tools throughout the world for fishery stock assessment (Gaertner et al. 2001; Haddon 2010). These models are very popular now-a-days as it only requires time series data of yield and effort instead of well-structured age data (Haddon 2010). Several researchers used various surplus production models to estimate catch per unit effort (CPUE), maximum sustainable yield (MSY) for both fishes and shellfishes around the world (Hilborn and Walters 1992; Chakraborty et al. 1997; Mehanna 2004; Prager 2002; Maunder et al. 2006; Mainardi 2010; Kalhoro et al. 2013; Siyal et al. 2013). While no previous research work has been documented on the yield of fishery resources of the Passur River, Bangladesh.

This study, therefore, attempted to estimate the MSY and corresponding fishing effort level $\left(f_{m s y}\right)$ for inland fish species considering the time series data of yield and catch of the Passur River fishery. Total allowable catch (TAC) with deterministic and stochastic error approaches was determined as well. The hypothesis of the study was to address whether the stock is being overexploited in the Passur River fishery. The results obtained from this study might be used as a reference to manage the Passur River fishery in a sustainable manner.

\section{MATERIAL AND METHODS}

Study area and period: The study was based on the fishery-dependent data recorded in the year from 2011 to 2014 for the Passur River, located in the southwest coastal region of Bangladesh. This river is connected with both the Bhairab and Rupsha River at up steam and finally, it falls into the Bay of Bengal by running through the Sundarban Reserve Forest (SRF). Passur River is 
considered to be the largest supplier of fresh-water to the SRF estuarine ecosystem (Rahaman et al. 2014).

Data collection: Fishery dependent data were collected from the Department of Fisheries (DoF) office, Khulna, Bangladesh. The data were based on the records of catch assessment survey focusing on the Passur River fishery. Other secondary information sources had been reviewed from different published journals and extension booklets in order to address particular issues and knowledge gaps.

Fishing operation: In the present study, only set bag net (SBN) was chosen because the net was mostly utilized for fishing in this river. The average length and depth of set bag net were $45.72 \mathrm{~m}$ and $4.57 \mathrm{~m}$ respectively. The mesh size was $0.025-0.038 \mathrm{~m}$ at the mouth and 0.064-0.076 $\mathrm{m}$ at the cod end. The time of operation was 6.00 A.M.-12.00 P.M. (at day) and 12.00 A.M.-6.00 A.M. (at night) and it covers about $334.45 \mathrm{~m}^{2}$ area.

Calculation of unit effort: Unit of effort was calculated in this study using the following equation:

Unit of effort $\approx($ Length $\times$ Depth $) \mathrm{m}^{2} \approx(45.72 \times 4.57) \mathrm{m}^{2} \approx 200 \mathrm{~m}^{2} \mathrm{SBN} /$ day

(Approx.)

MSY estimation: Initially, species wise total yield $(\mathrm{kg})$ and effort (units) data were estimated by using four-years records obtained from the surveyed (2 days in each month) catch assessment form. Then catch per unit effort (CPUE) was estimated by dividing the yield with corresponding effort and total CPUE was summed in accordance with Schaefer (1954) and Fox (1970) model.

Schaefer model: Catch per unit effort was calculated by the following model of Schaefer (1954):

$$
\operatorname{CPUE}=(Y / f)=a+b f
$$

Where $Y=$ Yield/catch; $f=$ fishing effort; $a$ and $b$ are constants whose values can be acquired from a linear regression of CPUE against fishing effort and the corresponding catch curve can be obtained using by the following equation:

$$
\text { Finally, MSY }=-\frac{a^{2}}{4 b} \text {, Optimum effort, } f_{m s y}=-\frac{a}{2 b}
$$

In addition, the TAC was assumed to be $90 \%$ of the MSY.

Fox model: In this model, natural logarithm is incorporated to convert the curve to a straight line.

$$
\ln [\mathrm{CPUE}]=\ln (Y / f)=a+b f
$$

In which, MSY and $f_{m s y}$ were calculated from the following equation,

$$
\mathrm{MSY}=(-1 / b) \exp [a-1] ; f_{m s y}=-1 / b
$$


Deterministic observation-error estimator: There are three methods widely used to fit the surplus production model. These are effort-averaging methods; process error estimators; and observation error estimators. In the present study, only observed-errors were considered in the model by assuming that all of the errors occurred in the relationship between stock biomass and the CPUE (Polacheck et al. 1993). The stock biomass was measured by projecting the initial yield forward under the estimated catches (Wu et al. 2010). Then, the CPUE was estimated by the following equation.

$$
\hat{I}_{t}=\hat{C}_{t} / f_{t}
$$

Where $\hat{I}_{t}$ is the estimated CPUE at year $t, f_{t}$ is the fishing effort during year t, $\hat{C}_{t}$ is the estimated catch at year $t$.

Stochastic observation-error estimator: A fixed observation-error was also applied in a stochastic approach following Monte-Carlo simulations. The simulation was applied in the present study to avoid the uncertainty in estimating fishing parameters. The simulation was constructed by drawing random values of the yields (Wu et al. 2010). In this model the standard deviation $(\sigma)$ was fixed at 0.01 and $1 \%$ random error of coefficient of variation (CV) was considered. The distributions for the model outputs such as the yield, MSY, and $f_{m s y}$ were based on 100 replications for inland fish species and the $100 \%$ were used as approximate $95 \%$ confidence intervals.

Data assessment: Data of the catch assessment records were coded and entered into a database system using Microsoft Excel-2010 and R software. Analysis and graphical presentation were also done by using same software. The results were prepared in ranking order with logical explanations.

\section{RESULTS AND DISCUSSION}

Species wise CPUE for the Passur river fishery: The estimated CPUE in the Passur River fishery was $1.35 \mathrm{~kg} /$ unit for the four years (Table1). The year-wise fishing effort was always same for different species but the yields were varying for their number of sample units. CPUE range from 0.00 (lower) to $0.38 \mathrm{~kg} /$ unit (higher). In this study, the inland fishes seem to be the most dominated group of fish species found in the selected river on the basis of the sampling data. Therefore, the present study considered only the inland fish species for further analysis and explanations. The estimated yield and CPUE for major inland fishes was $222.79 \mathrm{~kg}$ and $0.38 \mathrm{~kg} /$ unit effort respectively. The major inland fishes predominantly comprised of Chapila (Indian River Shad), Bacha (Eutropiichthys vacha), catfishes, tilapia (Mozambique tilapia), Silver carp (Hypophthalmicthys molitrix), thai pangas (Pangasius hypophthalmus), Sar-punti (Puntius sarana) and Poa (Pama croaker). 
Table 1. Estimation of CPUE by using four-years record for different major groups of species

\begin{tabular}{|c|c|c|c|c|c|c|c|c|c|c|c|}
\hline \multirow{3}{*}{$\begin{array}{c}\text { Major species } \\
\text { (group wise) }\end{array}$} & \multicolumn{8}{|c|}{ Yield \& Effort of sampling units by 4 years } & \multirow{3}{*}{$\begin{array}{l}\text { Total } \\
\text { yield } \\
(\mathrm{kg})\end{array}$} & \multirow{3}{*}{$\begin{array}{l}\text { Total } \\
\text { effort } \\
\text { (unit) }\end{array}$} & \multirow{3}{*}{$\begin{array}{c}\text { CPUE } \\
\text { (kg/unit) }\end{array}$} \\
\hline & \multicolumn{2}{|c|}{2011} & \multicolumn{2}{|c|}{2012} & \multicolumn{2}{|c|}{2013} & \multicolumn{2}{|c|}{2014} & & & \\
\hline & yield & effort & yield & effort & yield & effort & yield & effort & & & \\
\hline Major carps & 0.00 & 73 & 0.00 & 163 & 0.00 & 166 & 0.00 & 186 & 0.00 & 588 & 0.00 \\
\hline Other carps & 0.00 & 73 & 11.31 & 163 & 0.00 & 166 & 0.00 & 186 & 11.31 & 588 & 0.02 \\
\hline Catfishes & 12.75 & 73 & 39.88 & 163 & 15.20 & 166 & 0.00 & 186 & 67.83 & 588 & 0.12 \\
\hline Snake heads & 2.30 & 73 & 19.01 & 163 & 0.00 & 166 & 0.00 & 186 & 21.31 & 588 & 0.04 \\
\hline Live fishes & 0.00 & 73 & 17.62 & 163 & 0.00 & 166 & 0.00 & 186 & 17.62 & 588 & 0.03 \\
\hline Major inland & & & & & 41.75 & & 77.90 & & 222.7 & & \\
\hline fishes & 62.80 & 73 & 40.34 & 163 & & 166 & & 186 & 9 & 588 & 0.38 \\
\hline Hilsa & 0.00 & 73 & 0.28 & 163 & 0.00 & 166 & 0.00 & 186 & 0.28 & 588 & 0.00 \\
\hline Bombay duck & 6.20 & 73 & 27.40 & 163 & 8.20 & 166 & 0.00 & 186 & 41.80 & 588 & 0.07 \\
\hline Indian salmon & 0.00 & 73 & 2.32 & 163 & 0.00 & 166 & 0.00 & 186 & 2.32 & 588 & 0.00 \\
\hline Pomfret & 11.75 & 73 & 22.95 & 163 & 8.30 & 166 & 0.00 & 186 & 43.00 & 588 & 0.07 \\
\hline Sharks and & & & & & & & 0.00 & & & & \\
\hline & 0.00 & 73 & 0.50 & 163 & 0.90 & 166 & & 186 & 1.40 & 588 & 0.00 \\
\hline Others marine & & & & & & & 0.00 & & & & \\
\hline fishes & 5.50 & 73 & 16.42 & 163 & 8.10 & 166 & & 186 & 30.02 & 588 & 0.05 \\
\hline $\begin{array}{l}\text { Freshwater } \\
\text { shrimp }\end{array}$ & 065 & 73 & 0,00 & 163 & 0,00 & 166 & 950 & 188 & 1015 & 588 & 0.02 \\
\hline Tiger shrimp & 4.20 & 73 & 2.06 & 163 & 1.40 & 166 & 19.20 & 186 & 26.86 & 588 & 0.05 \\
\hline Other big & & & & & & & & & & & \\
\hline shrimp & 13.05 & 73 & 9.23 & 163 & 12.00 & 166 & 37.80 & 186 & 72.08 & 588 & 0.12 \\
\hline $\begin{array}{l}\text { Other small } \\
\text { shrimp (> } 10\end{array}$ & & & & & & & & & 207.6 & & \\
\hline $\mathrm{cm})$ & 40.35 & 73 & 63.04 & 163 & 30.95 & 166 & 73.30 & 186 & 4 & 588 & 0.35 \\
\hline Crabs & 8.70 & 73 & 9.11 & 163 & 0.00 & 166 & 0.00 & 186 & 17.81 & 588 & 0.03 \\
\hline Total & & & & & & & & & 794.22 & 9996 & 1.35 \\
\hline
\end{tabular}

Estimated parameters for inland fishes: Month wise CPUE, MSY, and $f_{m s y}$ for inland fishes were estimated and are shown in Table 2. The CPUE was ranged from $0.54 \mathrm{~kg} /$ unit in January to $0.28 \mathrm{~kg} /$ unit in September. The estimated fishing parameters for inland fishes using various models are as follows.

MSY and $f_{m s y}$ using Schaefer and Fox model: Relationship between CPUE and fishing effort $(f)$ applicable for the Schaefer model is shown in Fig. 1a); from the model, the intercept (a) and slope (b) were found 0.746 and -0.030 respectively. Similarly, the relationship between log-transformed CPUE and fishing effort $(f)$ applicable for Fox model and linear regression model are shown in Fig. 1 b); the intercept (a) and slope (b) were observed -0.076 and -0.074 respectively in this model. MSY and $f_{m s y}$ in Schaefer model was $4.66 \mathrm{~kg}$ and 12.49 units; in Fox model was $4.61 \mathrm{~kg}$ and 13.51 units respectively (Table 2). The results revealed that average yields of several months such as January $(6.62$ $\mathrm{kg})$, February $(5.15 \mathrm{~kg})$, March $(5.22 \mathrm{~kg})$, June $(4.73 \mathrm{~kg})$, July $(4.86 \mathrm{~kg})$ and December $(5.16 \mathrm{~kg})$ were higher than the obtained MSY. The fishing efforts at maximum sustainable yield were very similar for both models. However, the 


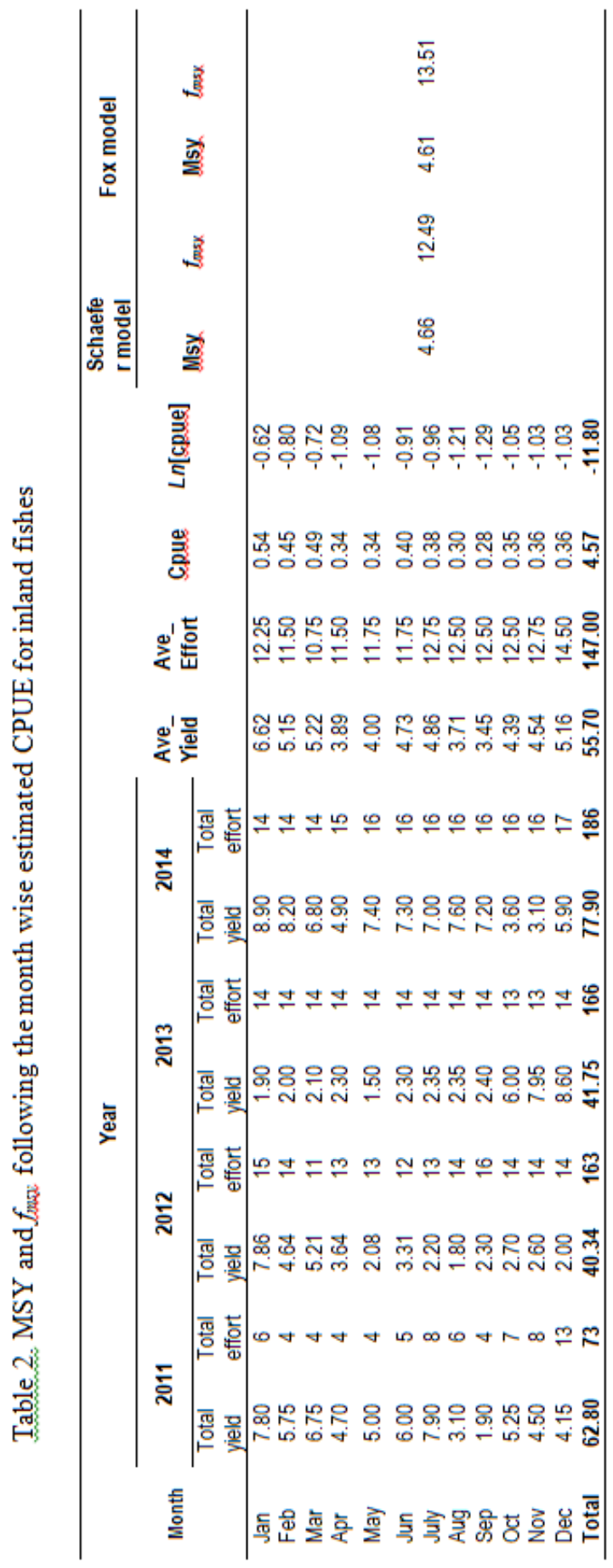



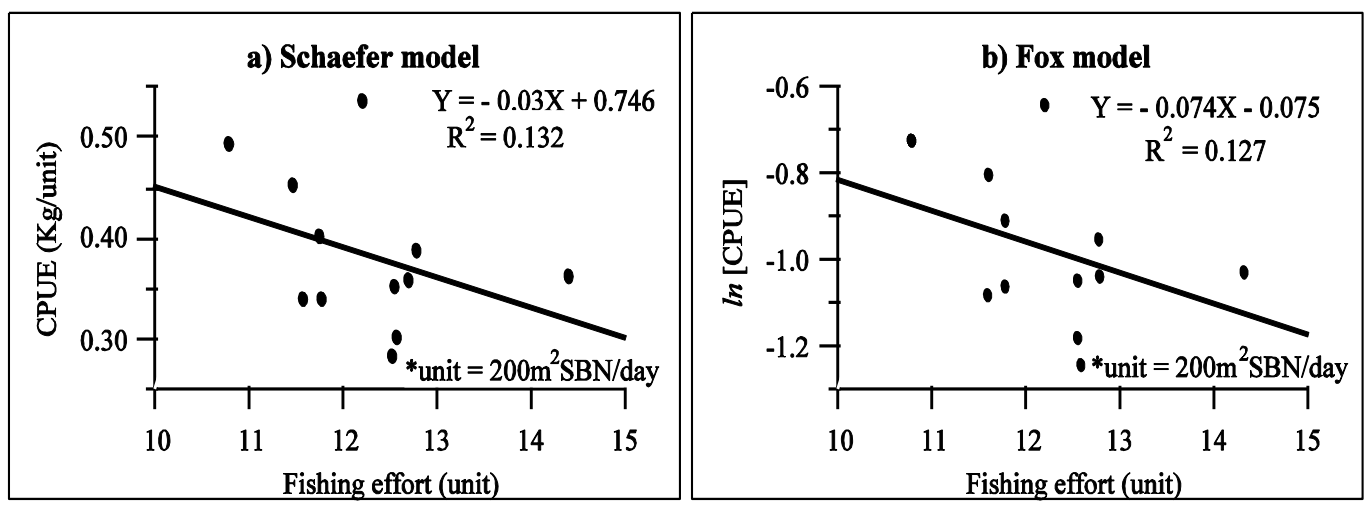

Fig. 1. Relationship between a) CPUE and fishing effort for Schaefer model and b) log-transformed CPUE and fishing effort for Fox model.

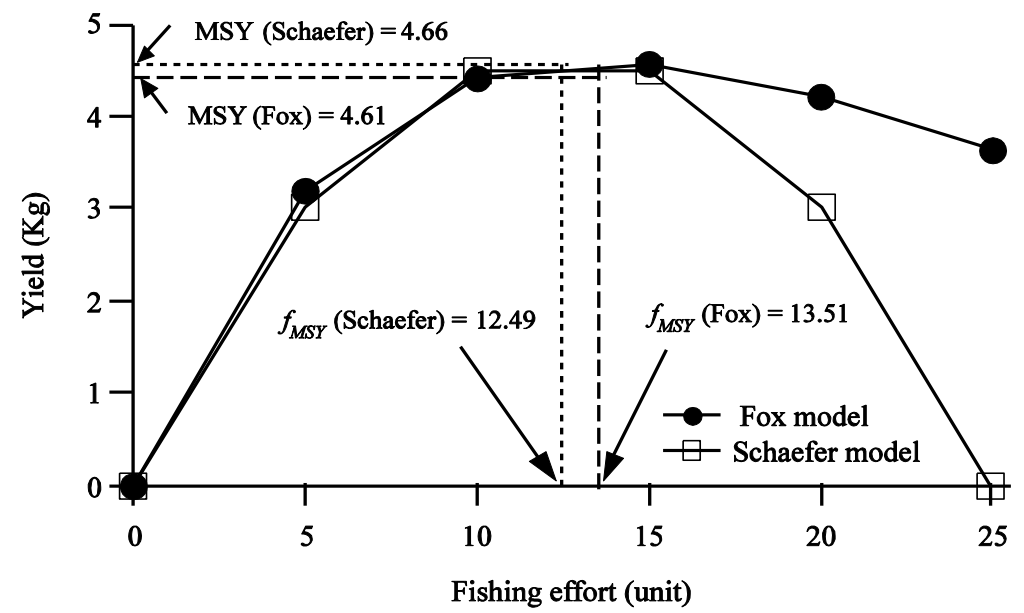

Fig. 2. Schaefer and Fox equilibrium yield curves

Schaefer model indicate a higher level of MSY than the Fox model (Table 2). Arbitrary value of effort and the respective yield on the basis of the obtained intercept and slope followed by Schaefer and Fox model are plotted in a graph (Fig. 2) to address the MSY and corresponding $f_{m s y}$. The estimated value of MSY $(4.61 \mathrm{~kg})$ and $f_{m s y}(13.51$ units) obtained by using Fox model was more accepted in this study since this model provides a better fit to data than Schaefer model (Sparre and Venema 1998) considering the obtained higher regression coefficient as well as its suitability with the Beaverton and Holt model (a recognized growth estimation model). Surplus production model especially Fox model was used by 
many researchers to analyze the MSY of few marine fishes (Kalhoro et al. 2013; Siyal et al. 2013).

According to Siyal et al. (2013), the stock seems to be overexploited if the obtained value of MSY is greater than the actual yield. In this study, the range of average catch in inland fishes was 3.45-6.62 kg with corresponding MSY of 4.61 $\mathrm{kg}$ (Table 2). This result indicated that the fish catch was higher than the MSY in several months like January, February, March, June, July, and December for inland fishes. Therefore, it is clearly visible that the Passur river fishery was being overexploited in these months. Similar conclusion on exploitation level of stock was drawn in many published literature (Siyal et al. 2013; Chakraborty et al. 1997; Mehanna 2004).

Various environmental factors such as temperature, salinity, precipitation and biological factors like life span, age, etc. affect the biomass of a stock (Wu et al. 2010). Since the surplus model does not include the details of these related factors, observation-error estimators might be one of the best ways that are being extensively used to fit the results of surplus production model. It is also used to minimize all the error occurs between the relationship of biomass and CPUE or MSY or TAC (Wu et al. 2010).

Deterministic observation-error estimator: Deterministic approach was utilized in this study to verify the fishing intensities obtained in the previous section. Estimated CPUE and $\mathrm{C}_{t} / \mathrm{MSY}$ for inland fish were calculated from the observed CPUE, MSY, and $f_{m s y}$. The estimation is shown in Table 3 . The observed CPUE fluctuated in the period of January to December, ranged from a

Table 3. Estimated CPUE, $\mathrm{C}_{t} / \mathrm{MSY}$ and $\boldsymbol{f}_{t} / f_{m s y}$ for inland fishes

\begin{tabular}{lcccccc}
\hline \multicolumn{1}{c}{ Month } & $\begin{array}{c}\text { Yield } \\
\text { (kg) }\end{array}$ & $\begin{array}{c}\text { Effort } \\
\text { (unit) }\end{array}$ & CPUE & $\begin{array}{c}\text { Estimate } \\
\text { CPUE }\end{array}$ & $\begin{array}{c}\mathbf{C}_{\mathbf{t}} / \mathbf{M S Y}= \\
\left(\mathbf{C}_{\mathbf{t}} / \mathbf{4 . 6 1} \mathbf{1}\right)\end{array}$ & $\begin{array}{c}\boldsymbol{f}_{\mathbf{t}} / \boldsymbol{f}_{\mathbf{m s y}}= \\
\left(\boldsymbol{f}_{\mathbf{t}} / \mathbf{1 3 . 5 1}\right)\end{array}$ \\
\hline January & 6.62 & 12.25 & 0.54 & 0.38 & 1.43 & 0.91 \\
February & 5.15 & 11.50 & 0.45 & 0.40 & 1.12 & 0.85 \\
March & 5.22 & 10.75 & 0.49 & 0.42 & 1.13 & 0.80 \\
April & 3.89 & 11.50 & 0.34 & 0.40 & 0.84 & 0.85 \\
May & 4.00 & 11.75 & 0.34 & 0.39 & 0.87 & 0.87 \\
June & 4.73 & 11.75 & 0.40 & 0.39 & 1.03 & 0.87 \\
July & 4.86 & 12.75 & 0.38 & 0.37 & 1.05 & 0.94 \\
August & 3.71 & 12.50 & 0.30 & 0.37 & 0.81 & 0.94 \\
September & 3.45 & 12.50 & 0.28 & 0.37 & 0.75 & 0.93 \\
October & 4.39 & 12.50 & 0.35 & 0.37 & 0.95 & 0.93 \\
November & 4.54 & 12.75 & 0.36 & 0.37 & 0.98 & 0.94 \\
December & 5.16 & 14.50 & 0.36 & 0.31 & 1.12 & 1.07 \\
Total & $\mathbf{5 5 . 7 0}$ & $\mathbf{1 4 7 . 0 0}$ & $\mathbf{4 . 5 7}$ & $\mathbf{4 . 5 6}$ & & \\
\hline
\end{tabular}

${ }^{*} \mathrm{C}_{t}=$ Estimated yield; ${ }^{*} f_{t}=$ Estimated fishing effort. 
peak of 0.54 in January to the lowest of 0.28 in September (Table 3). The estimated CPUE decreased slightly from the highest of 0.42 in March to the lowest of 0.31 in December. The observed CPUE was higher in January, February, March, June, July, and December than the estimated CPUE (Fig. 3). This estimation complies with the months of overfishing mentioned in the previous section except July. The observed CPUE in June and July were marginally higher than the estimated CPUE therefore, it can be concluded that the remarkable overfishing was from December to March, and marginal overfishing during June and July.

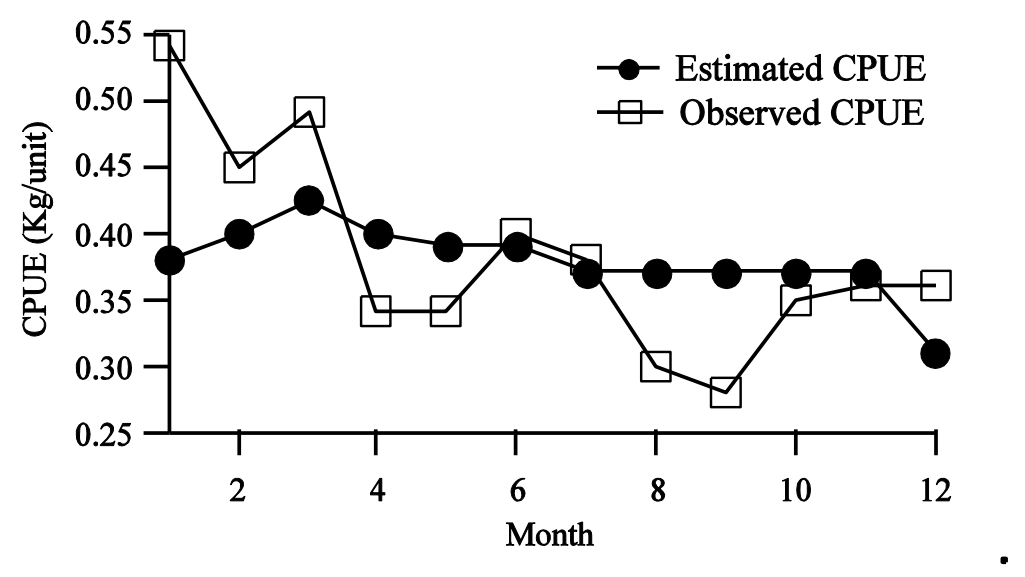

Fig. 3. The observed and estimated CPUE for inland fishes

The ratio of estimated yield $\left(\mathrm{C}_{t}\right)$ and MSY were less than $1\left(\mathrm{C}_{t} / \mathrm{MSY}=<1\right)$ in six (April, May, August, September, October, and November) months (Fig. 4) which revealed that the stock was not being overfished during these months. But the ratio of $\mathrm{C}_{t} / \mathrm{MSY}$ in others months were greater than $1\left(\mathrm{C}_{t} / \mathrm{MSY}=>1\right)$ i.e., there was overfishing in these months (January, February, March, June, July, and December). This estimation also complies with the overfishing months reported in previous section.

Stochastic observation-error estimator: The percentile confidence intervals and distributions of the three parameters (MSY, $f_{m s y}$, and TAC) were estimated

based on the stochastic model and are shown in Table 4. This Stochastic approach implied that the results obtained in MSY, $f_{m s y}$ and TAC for inland fish species in the current management measure with $95 \%$ CI but 5\% error were assumed in the present study. The mean MSY, TAC, and $f_{m s y}$ with $95 \%$ CI were 


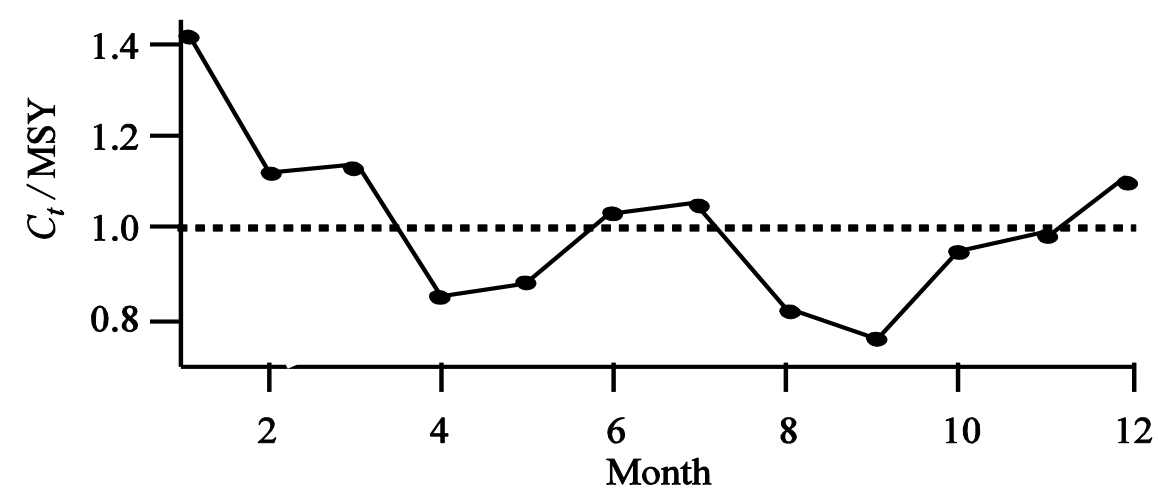

Fig. 4. The ratio of estimated yield $\left(\mathrm{C}_{t}\right)$ and MSY for inland fishes.

estimated to be $4.53(4.52-4.54) \mathrm{kg}, 4.08(4.07-4.09) \mathrm{kg}$, and 13.22 (13.1513.29) units respectively from the stochastic models (Table 4).

Table 4. Summary of output derived from Monte Carlo simulations for inland fish

\begin{tabular}{lccc}
\hline \multicolumn{1}{c}{ Stochastic } & MSY (kg) & $\boldsymbol{f}_{\text {msy }}$ (unit) & TAC (kg) \\
\hline Mean & 4.53 & 13.22 & 4.08 \\
95\% CI_UP & 4.54 & 13.29 & 4.09 \\
95\% CI_LOW & 4.52 & 13.15 & 4.07 \\
\hline
\end{tabular}

The stochastic results suggested that the mean of MSY $(4.53 \mathrm{~kg})$ was higher than TAC $(4.08 \mathrm{~kg})$ and it indicates that if the TAC is fully utilized for this fishery, it will ensure a long-term sustainability of this stock instead of overfishing occurrence. These results were analogous to the adjusted values estimated by Miao et al. (2006) and Wu et al. (2010).

\section{CONCLUSION}

Research on specific management measures was very much crucial for the sustainability of the Passur river fishery which was not yet been undertaken. This is the first study which addresses the MSY, $f_{m s y}$, overexploitation months, and TAC for the Passur River fishery. MSY of a stock used as a reference point to set an expected sustainable exploitation level of that stock. The obtained MSY in this study might be a milestone to represent the progress of population dynamics based work in the locality around the Passur river. Moreover, the total fish catch of the Passur River fishery will be equal to the estimated MSY, if current management measures like regulation on mesh size, restriction on 
harvesting juvenile and brood fishes, closures to protect the nursery grounds and licensing process are fully utilized. In addition, the TAC should be included in this management measures to ensure a long-term sustainable utilization of this stock and we assure that it will compensate the current level of overexploitation occurred in Passur River fishery towards achieving sustainable stock management goal.

Acknowledgements: The authors acknowledge the Department of Fisheries for their kind cooperation for providing the coastal fishery data. The authors declare that they have no conflict of interest.

\section{LITERATURE CITED}

ALLISON, E. H., and ELLIS, F. 2001. The livelihoods approach and management of small-scale fisheries. Mar. Policy, 25(5): 377-388.

CHAKRABORTY, S. K., DESHMUKH, V. D., KHAN, M. Z., VIDYASAGAR, K., and RAJE, S. G. 1997. Estimates of growth, mortality, recruitment pattern and maximum sustainable yield of important fishery resources of Maharashtra coast. Indian J. Mar. Sci., 26(1): 53-56.

CHOWDHURY, M. H. 2012. Pasur River. In: Banglapedia: National Encyclopedia of Bangladesh (Ed., Islam, S., and Jamal, A. A.). Asiat. Soc. Bangladesh, Bangladesh, pp.500.

DOF. 2015. National Fish Week 2015 Compendium (In Bengali). Department of Fisheries, Ministry of Fisheries and Livestock, Dhaka, Bangladesh. 148 pp.

FOX, W. W. 1970. An exponential surplus-yield model for optimizing exploited fish populations. Trans. Am. Fish. Soc., 99(1): 80-88.

GAERTNER, D., FONTENEAU, A., and LALOË, F. 2001. Approximate estimate of the maximum sustainable yield from catch data without detailed effort information: application to tuna fisheries. Aquat. Living Resour., 14(1): 1-9.

GAIN, D., SAROWER-E-MAHFUJ, M., SULTANA, S., and MISTRI, N. A. 2015. A preliminary study on fish fauna of the Passur River in Bangladesh. Int. J. Biodivers. Conserv., 7(7): 346-353.

HADDON, M. 2010. Modelling and Quantitative Methods in Fisheries. CRC press, Boca Raton, Florida, United States. Second ed., 450 pp.

HILBORN, R., and WALTERS, C. J. 1992. Quantitative fisheries stock assessment: choice, dynamics and uncertainty. Rev. Fish Biol. Fish., 2(2): 177-178.

IMTEAZZAMAN, A., and GALIB, S. 2013. Fish fauna of Halti beel, Bangladesh. Int. J. Curr. Res., 5(1): 187-190.

KALHORO, M. A., LIU, Q., MEMON, K. H., CHANG, M. S., and JATT, A. N. 2013. Estimation of maximum sustainable yield of Bombay Duck, Har-podonnehereus fishery in Pakistan using the CEDA and ASPIC packages. Pak. J. Zool., 45(6): 1757-1764. 
MAINARDI, S. 2010. Maximum Sustainable Yields and Non-Linear paths to steady-state equilibrium. Mar. Resour. Econ., 25(2): 185-212.

MAUNDER, M. N., SIBERT, J. R., FONTENEAU, A., HAMPTON, J., KLEIBER, P., and HARLEY, S. J. 2006. Interpreting catch per unit effort data to assess the status of individual stocks and communities. ICES J. Mar. Sci., 63(8): 1373-1385.

MEHANNA, S. F. 2004. Maximum sustainable yield of the round herring, Etrumeus teres and slimy mackerel, Scomber japonicus from the Gulf of Suez. Egypt. J. Aquat. Res., 30 (B): 322-325.

MIAO, S., JONG, J., and HUANG, C.-T. 2006. Economic analysis on management of TAC regarding Sakura shrimp fishery. J. Fish. Soc. Taiwan, 33(1): 35-43.

MOHSIN, A., HASAN, M., and GALIB, S. 2009. Fish diversity of community based fisheries managed oxbow lake (Bookbhara Baor) in Jessore, Bangladesh. J. Sci. Found., 7(1): 121-125.

POLACHECK, T., HILBORN, R., and PUNT, A. E. 1993. Fitting surplus production models: comparing methods and measuring uncertainty. Can. J. Fish. Aquat. Sci., 50(12): 2597-2607.

PRAGER, M. H. 2002. Comparison of logistic and generalized surplus-production models applied to swordfish, Xiphias gladius, in the north Atlantic Ocean. Fish. Res., 58(1): 41-57.

RAHAMAN, S. M., BISWAS, S. K., RAHAMAN, M. S., GHOSH, A. K., SARDER, L., SIRAJ, S., et al. 2014. Seasonal nutrient distribution in the Rupsha-Passur tidal river system of the Sundarbans mangrove forest, Bangladesh. Ecol. Process., 3(1): 18.

SCHAEFER, M. B. 1954. Some aspects of the dynamics of populations important to the management of the commercial marine fisheries. Inter-Amer. Trop. Tuna Comm. Bull., 1(2): 23-56.

SIYAL, F. K., LI, Y., GAO, T., and LIU, Q. 2013. Maximum sustainable yield estimates of silver pomfret, Pampus argenteus (Family: Strometidae) fishery in Pakistan. Pak. J. Zool., 45(2): 447-452.

SPARRE, P., and VENEMA, S. 1998. Introduction to tropical fish assessment. FAO Fish. Tech. Paper., Rome, Italy. Vol. 306/1, Second ed., 407 pp.

WU, C.-C., OU, C.-H., TSAI, W.-P., and LIU, K.-M. 2010. Estimate of the maximum sustainable yield of sergestid shrimp in the waters off Southwestern Taiwan. J. Mar. Sci. Technol., 18(5): 652658.

(Manuscript received on 29 September, 2020 revised on 22 October, 2020) 